\title{
WISATA ALAM LIAR
}

\author{
Dhea Bella ${ }^{1)}$, Franky Liauw ${ }^{21}$ \\ 1) Program Studi S1 Arsitektur, Fakultas Teknik, Universitas Tarumanagara, dheabellaa@gmail.com \\ 2) Program Studi S1 Arsitektur, Fakultas Teknik, Universitas Tarumanagara, frankyl@ft.untar.ac.id
}

\begin{abstract}
Abstrak
Jakarta sebagai kota metropolitan dengan penduduk mencapai 10,37 juta jiwa pada tahun 2017 telah menggusur keberanekaragaman flora dan faunanya. Hal ini terbukti dari hilangnya salah satu Maskot DKI Jakarta yang ditetapkan melalui Keputusan Gubernur No. 1796 Tahun 1989 yaitu Elang Bondol dari langit Jakarta. Hilangnya species ini disebabkan karena penggusuran habitat, terputusnya rantai makanan dan kurangnya pengertian dimana pada dasarnya manusia merupakan bagian dari alam yang harusnya segala kegiatannya berkesinambungan dengan alamnya. Proyek Wisata Alam Liar (Urban Wildlife Park) selain bermaksud untuk mengembalikan identitas kota Jakarta, juga membuka kesempatan untuk membuat lingkungan buatan yang tidak hanya digunakan untuk manusia seperti pada umumnya, namun dapat bersinergi dengan spesies lain yang berada didalamnya. Sehingga arsitektur dapat berkonstribusi kepada alam dan berkembang ke arah berkelanjutan, serta dapat menambahkan prosentase ruang terbuka hijau seperti yang ditetapkan oleh Pemprov DKI yang kini baru mencapai 9,98\% dari target 30\% total luas wilayah DKI Jakarta.
\end{abstract}

Kata kunci: wisata, ekologi, flora dan fauna, rantai makanan.

\begin{abstract}
Jakarta as a Metropolitan city with a population reaching 10.37 million in 2017 has displaced its biodiversity. This is proven by the loss of one of the DKI Jakarta Mascots determined by the Decree of Governor No. 1796 of 1989 - Brahminy Kite from the sky of Jakarta. The loss of this species is caused by the eviction of habitats, the breakdown of the food chain and the lack of understanding where basically human beings are part of the natural environment which must be carried out in a sustainable manner with nature. The "Urban Wildlife Park" project in addition to intending to restore the identity of the city of Jakarta, also opens the opportunity to create an artificial environment that is not only used for humans as in general, but can synergize with other species inside. So that architecture can contribute to nature and develop in a sustainable direction. As well as adding the percentage of green open space as determined by the DKI Provincial Government (Jakarta's Green Open Space has only reached $9.98 \%$ of the target of $30 \%$ of the total area of DKI Jakarta)
\end{abstract}

Keywords: tourism, ecology, biodiversity, food web.

\section{PENDAHULUAN (11pt)}

Sejak tahun 2008 lebih banyak orang tinggal di kota daripada pedesaan. Meningkatnya pertumbuhan suatu kota merupakan momen besar dalam sejarah manusia, dan itu berarti salah satu dari dua hal: baik hubungan manusia dengan alam akan terus memudar, atau itu berarti awal dari jenis kota yang baru. Jakarta sebagai ibu kota Indonesia dengan 10.37 juta penduduk pada tahun 2017 merupakan salah satu kota metropolis yang faktanya pada saat ini lingkungan buatan telah mengisi $80 \%$ lahan dari lingkungan alami di dunia. Di Jakarta sendiri, menurut data dari Indonesia Property Watch (IPW), dari 5 wilayah yang ada di Jakarta, hanya Jakarta Timur yang masih menyisakan lahan kosong, itupun mayoritas sudah dikuasai pihak swasta.

Urbanisasi di Jakarta menyebabkan spesies hewan dan tumbuhan yang ada terancam. Salah satu contohnya adalah Elang Bondol (Haliastur indus) yang dulu sangat mudah di temukan di langit Jakarta. Elang Bongol adalah maskot DKI Jakarta yang ditetapkan melalui Keputusan Gubernur No. 1796 Tahun 1989 ini pindah karena makanan favoritnya berupa ikan yang berada di perairan bersih sudah tidak tersedia lagi di Jakarta, dimana agar tidak kelaparan, 
elang bondol harus belajar makan bangkai hewan pengerat yang mati tertabrak kendaraan bermotor dimana ia sama sekali tidak menyukai jenis makanan ini sebelumnya. Hal ini terjadi karena manusia merasa dirinya bukan bagian alam sehingga lingkungan buatan yang ada pada saat ini justru mendukung hilangnya kesempatan manusia untuk memahami posisinya sebagai makhluk hidup yang beretika dan menghormati alamnya. Padahal seharusnya first nature (natural) tidak dapat dipisahkan dengan second nature (buatan manusia), walaupun apa yang kita tinggali saat ini adalah sebuah kota metropolis.

Jakarta yang dulunya merupakan hutan dan rawa-rawa hanya seperti mitos jika melihat keadaan saat ini dikarenakan hampir seluruh flora dan fauna di Jakarta telah berpindah dan digantikan dengan hutan beton. Masyarakat perlu sadar, ini bukan tentang ruang hijau atau hewan apa yang mereka inginkan, melainkan ekosistem seperti apa yang mereka inginkan dari ruang hijau dan hewan. Mengembalikan alam Jakarta dengan menggabungan aktifitas antara manusia dan alam dapat menjadi solusi untuk menjaga ekosistem Jakarta. Di sisi lain, hal ini dapat mengembalikan identitas dan keunikan Jakarta yang telah hilang. Selain itu, ini juga merupakan kesempatan untuk membuat lingkungan buatan yang tidak hanya digunakan untuk manusia seperti pada umumnya, namun dapat bersinergi dengan spesies lain yang berada didalamnya. Sehingga arsitektur dapat berkonstribusi kepada alam dan berkembang ke arah berkelanjutan. Arsitektur dapat dioleh secara fleksibel dan kreatif untuk mengembalikan habitat alam yang akhirnya menciptakan dan mengembalikan rantai makanan yang dapat menjaga keseimbangan ekosistem dengan keragaman hewan dan tumbuhan yang utuh (biodiversity).

Meskipun daratan Indonesia hanya menutupi 1,3\% dari permukaan Planet Bumi, secara global negara kita merupakan rumah bagi $12 \%$ mamalia, $16 \%$ reptil dan amfibi, $17 \%$ burung, $10 \%$ tanaman berbunga, serta $25 \%$ spesies ikan. Hal ini meningkatkan optimism bahwa kota dapat menjadi "engines of biodiversity" - mesin keanekaragaman hayati. Biodiversity yang diciptakan melalui lingkungan buatan yang terinspirasi oleh alam bertujuan untuk mengembalikan habitat hewan dan tumbuhan asal Jakarta dan yang dapat hidup di Jakarta demi menjaga kestabilan ekosistem dan sebagai ilmu pengetahuan dalam wujud arsitektur dan landscape pada program wisata ekologi. Bukan bertujuan untuk menjadi kebun binatang atau cagar alam yang berusaha menampilkan seluruh kekayaan alam Indonesia, yang pada faktanya dapat menyiksa hewan dan tumbuhan yang tidak cocok untuk hidup di Jakarta, melainkan menciptakan ekosistem yang terdiri dari hewan dan tumbuhan yang nyaman untuk hidup dan di Jakarta dengan rantai makanan seperti yang semestinya.

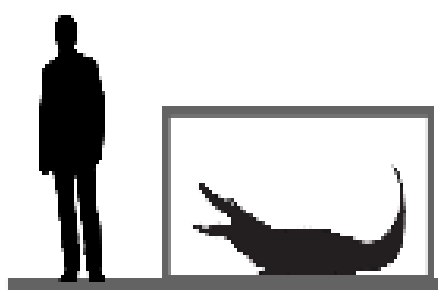

200

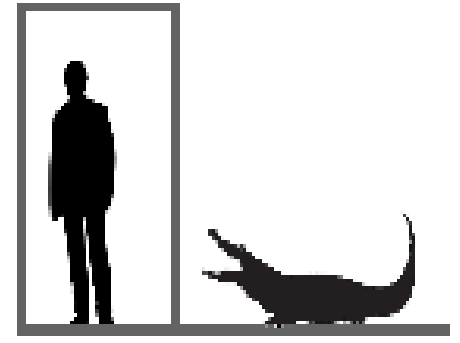

tadisicnal setar

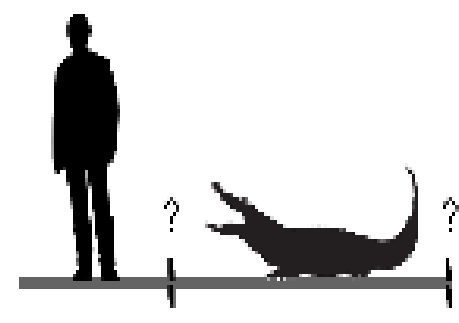

rodivm sakfar?

Gambar 1. Zoo dan Safari

\section{METODE}

Penelitian ini dilakukan dengan metode studi literatur, studi observasi, dan wawancara. Studi literatur yang dilakukan berupa pencarian data terkait proyek dan data yang mendukung dalam pemilihan tapak. Seperti meneliti pergerakan atau siklus migrasi burung, dan lokasi burung yang terisolasi di Jakarta sehingga membentuk suatu pola sehingga didapatkan opsi 
pemilihan tapak. Observasi yang dilakukan berupa pengamatan pada lokasi burung yang terisolasi untuk mendapatkan jenis-jenis burung yang terisolasi, pengamatan langsung di lokasi opsi tapak dan pengamatan pada tapak yang terpilih. Wawancara dapat dilakukan untuk melengkapi data-data mengenai tapak yang terpilih.

\section{DISKUSI DAN HASIL}

\section{Permasalahan Flora dan Fauna Jakarta}

Perpindahan spesies yang terjadi selama ini menyebabkan hilangnya salah satu identitas kota Jakata, Elang Bondol hanya seperti mitos. Perpindahan spesies ini juga membuat suatu pertanyaan, berpindah kemanakah elang bongol dan spesies lainnya? Apakah ada yang bisa manusia lakukan sebagai subjek yang menggusurnya untuk melindungi tetangga non-manusia Jakarta? Karena permasalah ini bukan seperti burung dari Jakarta yang terbang dan berwisata ke Bogor, tapi manusia mengubah landscape sehingga rantai makanan dan spesies hewan pun punah atau berpindah. Perpindahan spesies ini dapat berdampak pada zoonosis yang berpotensi menjadi wabah. Namun bukanlah mustahil untuk mengembalikan flora dan fauna yang dulu merupakan penghuni Jakarta. Dengan adanya pembuatan kembali habitat yang dulu pernah ada di Jakarta dan rantai makanan yang lengkap maka flora dan fauna akan dapat hidup di Jakarta.

Merupakan suatu tantangan dimana kondisi Jakarta sudah tidak seperti dulu lagi. Kesadaran akan pentingnya sebuah desain yang cocok dengan kehidupan masyarakat sekarang yang juga dapat menjadi sebuah peluang untuk memperbaiki hubungan manusia dengan alamnya. Untuk mencapai hal tersebut maka harus ada konsepsi ruang berupa lingkungan yang dibuat dengan mempertimbangkan aktivitas flora dan fauna, keberlangsungan rantai makanannya, dan manusia. Sebuah bentuk yang dinamis perlu diupayakan sehingga manusia dapat berinteraksi dengan alam. Suatu karya arsitektur yang tidak memenjarai hewan (kebun binatang), tidak memenjarai manusia (taman safari), melainkan menjadikan flora-fauna bisa hidup berdampingan dengan manusia yang tentunya tetap ada batasan baru digunakan menjadi ide dan tujuan perencaan proyek ini.

Berdasarkan penjabaran diatas, tujuan dan manfat dari proyek ini antara lain:

- Mengembalikan identitas Jakarta yang telah terlupakan

- Memberikan fasilitas hiburan dan rekreasi pada bidang ekologi yang juga dapat mengedukasi masyarakat

- Menyatukan manusia dengan alam seperti sebagaimana seharusnya

- Menjaga keseimbangan ekosistem Jakarta dengan menciptakan rantai makanan, sehingga dapat mencegah kepunahan dan penyebaran wabah zoonosis

Proyek dirancangan dengan dasar analisis kawasan dan lingkungan sekitar untuk mengetahui kebutuhan dan masalah yang terjadi di Jakarta. Metode yang digunakan adalah superimposition yang merupakan gabungan dari beberapa habitat yang tercipta karena adanya pemisahan flora-flora, fauna-fauna, ataupun flora dan fauna dan eksperimental dalam penggabungan program ruang.

Pentingnya koridor burung Jakarta disadari Pemprov DKI Jakarta sejak 2014 dengan penambahan Ruang Terbuka Hijau (RTH) dan adanya perancangan rute koridor burung Jakarta yang dibuat berdasarkan lokasi burung yang terisolasi. Berikut peta burung yang merupakan pengabungan dari lokasi burung yang terisolasi di Jakarta dan rencana koridor burung Pemprov DKI Jakarta yang menghasilkan suatu jalur yang berkesinambungan antara satu sama lain (Gambar 2). Namun jika di perhatikan lebih jelas, terdapat jarak yang pada titik-titik di Jakarta Selatan. Sehingga jarak inilah yang menjadi opsi kawasan pada proyek Urban Wildlife Park dimana proyek ini diharapkan dapat berkontribusi pada perkembangbiakan fauna Jakarta. 


\section{Lokasi dan Tapak}

Jakarta yang dulunya merupakan hutan menjadi salah satu tempat pemberhentian para burung migrasi sebelum melanjutkan perjalanan. Selain migrasi besar antar pulau, di Jakarta sendiri pun terdapat migrasi lokal dimana burung-burung dapat berkeliling Jakarta untuk mencari makan dan mencari pasangan.

Faktanya saat ini di langit Jakarta jarang ditemui burung yang sedang bermigrasi. Hal ini karenakan terputusnya koridor burung sehingga burung migrasi kembali ke tempat asalnya atau terisolasi di titik-titik Jakarta bersama burung-burung lokal lainnya. Perlunya koridor burung Jakarta sebagai tempat singgah dikarenakan burung tidak berani terbang jika tidak dapat melihat tempat pemberhentiannya (jalur hijau di sepanjang jalan tidak hitung), dan hanya beberapa jenis burung yang dapat beradaptasi dan hinggap di genteng perumahan ataupun tiang listrik. Terisolasinya burung-burung tersebut menyebabkan terjadinya perkawinan sedarah yang menyebabkan kecatatan pada keturunan selanjutnya.

\section{Gambar 2. Analisa Kawasan}

Sumber: Olahan Penulis, 2018

Tapak terpilih berada pada Jl. Mampang Prapatan dan Jl, Kemang Utara, kecamatan Pancoran, kelurahan Duren Tiga, Jakarta Selatan. Pemilihan tapak selain didasarkan pada kebutuhan sesuai dengan koridor burung Jakarta juga dikarenakan area Kemang dulunya merupakan hutan pohon kemang (Mangifera kemanga) yang mulai langka di Indonesia. Dengan pemilihan tapak pada area ini diharapkan dapat menjadi salah satu upaya pelestarian. Sementara itu, penginjeksian program flora dan fauna di tengah kawasan perkotaan diharapkan dapat membawa pengembangan performa arsitektur. Relasi dengan alam yang terjalin dapat menyusup kedalam budaya dan gaya hidup masyarakat urban.

\section{Konsep Perancangan dan Pendekatan Desain}

Penerapan architourism of the metropolis dengan mengangkat tema wisata ekologi sebagai salah satu daya tarik wisata di Jakarta digunakan sebagai pemikiran utama dalam proyek ini. Perancang membuat desain dengan konsep "rantai makanan" atau "food web", yang kemudian diterjemahkan secara programatik maupun arsitektural. Dalam penerapan rantai makanan sebagai konsep utama; flora dan fauna dapat hidup dengan nyaman dan tidak kehilangannya instingnya sebagai makhluk yang dapat bertahan hidup. Untuk mencapai tujuan tersebut dilakukan studi maket dalam pembentukan gubahan massa. Gubahan massa dibuat dengan memprioritas kenyamanan hewan sehingga dibuat fungsional, adanya ramp sebagai sirkulasi utama pengunjung dibuat sebagai penggabungan program. Sebagai bentuk keseluruhan digunakan metode surealis, dimana penggabungan program dengan ramp dibuat sedemikian rupa sehingga membentuk suatu bentuk yang bernilai seni namun tetap fungsional sebagai platform pengamatan/ observasi.

Gambar 3. Food Web

Sumber: Olahan Penulis, 2018

Dalam perancangan proyek ini, poin sirkulasi yang terjadi didalamnya menjadi hal yang utama. Terdapat 2 model sirkulasi yaitu, sirkulasi hewan dan sirkulasi pengunjung. Sirkulasi hewan dibuat berdasarkan rantai makanannya dimana tumbuhan dan hewan makanannya berada saling berkesinambungan. Perancangan proyek Wisata Alam Liar (Urban Wildlife Park) dibuat vertikal agar ruang terbuka hijau (RTH) dapat menjadi lebih besar 
sehingga berguna sebagai fasilitas umum, sehingga lantai dasar bangunan dapat di akses masyarakat tanpa harus membayar tiket masuk wisata. Hal ini guna mendukung program edukasi masyarakat akan flora dan fauna.

Selain itu perlu adanya pemisahan yang jelas pada beberapa jenis binatang sehingga pemisahan tersebut dibuat secara vertikal. Pemisahan ini dikarenakan kebutuhan binatang yang berbeda-beda. Contohnya perbedaan terang-gelap, kelembaban, dan lain-lain. Selain pemisahan ada pula pengabungan beberapa jenis tumbuhan. Umumnya strategi ini dilakukan pada tanaman yang dapat berperan sebagai peneduh. Setiap lantai dihubungkan dengan void bangunan sehingga burung dapat berpindah dari satu pohon ke pohon lainnya demi memenuhi kebutuhannya, namun binatang lainnya dapat berpindah sesuai dengan siklus rantai makanannya.

Sistem struktur yang digunakan untuk menunjang bentuk form bangunan adalah sistem kolom-balok dan plat slab dimana plat dapat sebagai lantai dan juga struktur dalam bangunan. Plat slab yang digunakan merupakan pencampuran antara structural concrete dan bioconcrete demi mempermudah perawatan bangunan.

Gambar 4. Konsep Perancangan dan Perencaan Zoning

Sumber: Olahan Penulis, 2018

Gambar 5. Pengolahan Site Plan

Sumber: Olahan Penulis, 2018

Gambar 6. Potongan Perspektif

Sumber: Olahan Penulis, 2018

Gambar 7. Gambar Perspektif Eksterior dan Interior

Sumber: Olahan Penulis, 2018

\section{KESIMPULAN DAN SARAN}

Proyek ini diharapkan dapat berdampak dan membawa perubahan yang baik pada kawasan Pancoran maupun Kota Jakarta; menyadarkan masyarakat bahwa manusia tidak dapat terlepas dari alamnya sehingga lingkungan buatan tidak hanya digunakan untuk kebutuhan manusia, melainkan dapat bersinergi dengan spesies lain yang berada didalamnya.

Arsitektur dapat berkontribusi kepada alam untuk mengembalikan habitat alam yang akhirnya menciptakan dan mengembalikan rantai makanan yang dapat menjaga keseimbangan ekosistem dengan keragaman hewan dan tumbuhan yang utuh (biodiversity) sebagai bagian dari identitas kota Jakarta. 


\section{UCAPAN TERIMA KASIH}

Dalam proses studi dan perancangan proyek Wisata Alam Liar (Urban Wildlife Park), peneliti ingin menyampaikan ucapan terima kasih kepada Tuhan Yang Maha Esa, atas bimbingan dan penyertaan-Nya dan pihak-pihak yang telah membantu dalam proses yang dilakukan, yaitu kepada: Dosen Pembimbing Utama, Dosen Pembimbing Pendamping, Dosen Koordinator Stupa 8.26, Dosen Pembimbing Tugas Akhir lainnya, Ketua Program Studi Sarjana Arsitektur, Ketua Jurusan Arsitektur dan Perencanaan Fakultas Teknik Universitas Tarumanagara dan Pihak-pihak lainnya yang telah memberikan pengarahan, petunjuk dan bimbingan yang memungkinkan terselesaikannya artikel ini.

\section{REFERENSI}

Almusaed, Amjad. (2011). Biophilic and Bioclimatic Architecture - Analytical Therapy for the Next Generation of Passive Sustainable Architecture. New York: Springer London Dordrecht Heidelberg New York.

Baihaqi, Ahmad, dkk. (2015). Geledah Jakarta, Menguak Potensi Keanekaragaman Hayati Ibukota. Jakarta: Kehati

Dekranasda (Dewan Kerajinan Nasional Indonesia) Provinsi DKI Jakarta. (2017). Lenggang Batik Jakarta . Jakarta: Gramedia Pustaka Utama

Environmental Protection Authority - Te Mana Rauhi Talao. (2018). Standard fo Zoo Containment Facilities

Holt, Steve. (2017). Where Do Urban Animals Go When Their Habitats Disappear? https://www.citylab.com/environment/2017/11/where-do-urban-animals-go-when-their-habitatsdisappear/546002/, diakses July 2018

Horward, Brian Clark. (2013). Connecting with Nature Boosts Creativity and Health, https://news.nationalgeographic.com/news/2013/06/130628-richard-louv-nature-deficitdisorder-health-environment/, diakses July 2018https://www.terrapinbrightgreen.com/reports/14patterns/\#front-matter, diakses July 2018

Kristanto, Ady. (2008) . Alam Jakarta Panduan Keanekagaraman hayati di Jakarta. Jakarta: Murai Kencana.

Peraturan Menteri Lingkungan Hidup dan Kehutanan RI No. P.20/MENLHK/SEKJEN.KUM.1/6/2018 tentang Jenis Tumbuhan dan Satwa yang Dilindungi

PPRI Nomor 7 tahun 1999 tentang Pengawetan Jenis Tumbuhan dan Satwa

Septian, Reza. (2017). Indonesia Adalah Jalur Penting Migrasi Burung, Anda Mengetahui? http://www.mongabay.co.id/2017/05/23/indonesia-adalah-jalur-penting-migrasi-burung-andamengetahui/, diakses Agustus 2018

Sofian, Arnaz. (2018). RTH DKI Jakarta Masih Jauh dari Target, https://www.liputan6.com/news/read/3488105/foto-rth-dki-jakarta-masih-jauh-dari-target?page=1, diakses July 2018.

Specht, Jan. (2014). Architectural Tourism - Building for Urban Travel Destination. Germany: Springer Gabler

Suryowati, Catherina. (2013). Persebaran Burung di Koridor Hijau Jalan - Studi Kasus di Koridor Hijau Jalan di Jakarta. Universitas Indonesia. Depok.

Wihardandi, Aji. (2013). Elang Bondol: Sang Pemangsa Tersingkir oleh Hutan Beton Jakarta. http://www.mongabay.co.id/2013/08/01/elang-bondol-sang-pemangsa-tersingkir-oleh-hutanbeton-jakarta/, diakses July 2018 